\title{
Understanding the Social Distance and Prejudice of Diponegoro University Students in Intimate Relationships Towards Disability Group
}

\author{
Lintang Ratri Rahmiaji ${ }^{1}$, Hapsari Dwiningtyas Sulistyani², Turnomo Rahardjo ${ }^{3}$ \\ \{lintangratri84@gmail.com $\left.{ }^{1}\right\}$ \\ Universitas Diponegoro, Indonesia ${ }^{1,2,3}$
}

\begin{abstract}
This research is a quantitative survey study conducted to measure social distance and prejudice of Diponegoro University students in intimate relationships, in the contexts of friendship and marriage towards those who come from disability groups. This study involved 415 students, with simple random sampling technique, from 31,481 active students of Diponegoro University in 2019. They consist of 283 women and $132 \mathrm{men}$. The results of this study is that there is significant differences between men and women when it comes to intimated relationships towards disability group, in contexts of marriage. In terms of friendships, there is no differentiation between men and women, both of gender has no social distance with disability group. The study also found that the percentage of women higher than men refers to unwillingness marriage with persons who has disability. The main argumentation is that because men in patriarchal culture (like in Indonesia) are expected to be the head of the family. The rejection to get married to someone with disability indicates about social prejudice in the form of discrimination.
\end{abstract}

Keywords: Social Distance, Prejudice, Intimate Relationships, Disability Group

\section{Introduction}

In this article, the research was conducted to measure social distance and prejudice of Diponegoro University students in intimate relationships, in the contexts of friendship and marriage towards those who come from disability group. Human nature needs affiliation, especially in times of fear and uncertainty. This explains why someone builds and maintains interpersonal relationships, such as friendships. Humans also need intimacy, and a need to belong. This need explains why everyone wants to have friends, have a partner, and be part of a group [1]. Love, romance, sexuality, and marriage is part of the field's emerging concern for developing the richest possible conception of human actors at play on all of life's stages [2]. Sullivan [3] intimate relationship plays an important role in the process of adolescent development, namely the development of identity, transformation of family relationships, establishing relationships with peers, development of sexuality, achievement and career planning. One indication of the development of adolescent psychology is the ability to form new and more mature relationships with the opposite sex [4].

However, in reality, not all humans have the same opportunity to build intimate relationships with the opposite sex, for example, individuals with physical and mental disabilities. Apart from the need for friendship and romantic relationships, persons with disabilities face a number of social relationship gaps [5][6]. In the context of cultural 
communication, inclusiveness is built through intercultural interaction. Various social constraints such as stereotypes, prejudices, and discrimination are closely related to the social distance that is the focus of this research. Distance here is not understood as distance or biological/genetic distance. The concept of social distance is proposed by Bogardus. According to Bogardus [7], feelings of sympathy and affection are key elements of social distance: when there is little understanding and sympathy, there arises social distance. Conceptually, prejudice can be expressed in several ways, either vague or indirect or direct prejudice [8]. The expression of prejudice based on the results of Allport's study is antilocution, avoidance, discrimination, physical attack, and extermination. Persons with disabilities, even those living in communitybased environments, often have fewer opportunities to meet people. People with mental disabilities are the most vulnerable to social isolation [9].

A national survey study involved 15,073 respondents in Denmark, aged between 26 and 65 of whom 4102 reported physical disabilities and 1174 mental disabilities. An interesting finding is that participants with disabilities (physical, mental, or both) reported significantly lower levels of sexual activity and satisfaction than participants without disabilities, while respondents with disabilities reported the lowest levels of sexual activity and satisfaction [10].

People with mental disabilities often have fewer opportunities to make and maintain friendships. Friendship predicts better outcomes in almost every area of a person's life. Therefore, it is very important to encourage the development, maintenance and growth of friendship for people with mental disabilities [11]. Persons with disabilities have been unfairly labeled negative, subordinated to restriction or denial and appear to be "not allowed to love", among others being prevented from having friendships, having relationships and from raising their children [12]. The notion of persons with disabilities tends to be seen as "personal pathologies, individual difficulties and dependencies in coping with treatment". Regarding sexuality and romantic intimate relationships, there are still dominant narratives of women with disabilities as potential victims and men as potential aggressors [13].

There is a research about changes in values and community orientation in accepting disabilities [14]. Analysis in this journal states that some people in general tend to reject or less accept the existence of people with disabilities. The tendency for rejection by some of the community is associated with changes in the values and orientation of society. Where the values and orientation of society today are more inclined and put forward in prioritizing physical appearance [14]. On previous survey, Sulistyani et al. [15], found that most students from the 12 faculties don't have social distance towards disability group. Overall, in terms of the faculties at Undip, the least distant to group with disabilities both physically and mentally is the Faculty of Engineering, while the one with the highest social distance is the Vocational School. It shows the potential for conflict and resistance from Undip students towards the minority group around them.

Whereas according to Chernomas, Clarke and Marchinko [16] people with mental disabilities, having an intimate relationship with people with other disabilities can result in greater self-acceptance, less internalized stigma, and more friendship. In addition, intimate relationships with peers with disabilities can help persons with disabilities when they face a world that is discriminatory to persons with disabilities. A synergistic system is needed to help persons with disabilities lead a decent life, for example collaboration between formal mental health services, social services, and self-help groups, or other networks such as food banks and church groups [16]. Social institution should also make these initiatives people-centered and individualized rather than one size fits all to maximize equality - to ensure equal access to sexual opportunities for adults with disabilities if they wish to. University as the highest educational 
institution should play a role in ensuring equal rights for persons with disabilities to have healthy interpersonal relationships.

\section{Methods}

This research was built within the framework of the positivism paradigm, which prioritizes empirical truth, and sees reality as outside human beings, and therefore is value free. The positivist paradigm uses deductive logic and probabilistic measurements aimed at confirming the law of causality which is able to predict general patterns of certain social symptoms so that human behavior can be controlled [17].

This research was conducted with a quantitative approach in which the concept is operationalized into measurable variables, the resulting data is in the form of numbers, is general in nature and must be tested for its validity and reliability. The data collection method is in the form of a survey and analyzed descriptively. This study involved 415 students, with simple random sampling technique, from 31,481 active students of Diponegoro University in 2019. They consist of 283 women and 132 men. At the operational level, this methodology is the basis for explaining and predicting the behavior of Diponegoro University students in managing interpersonal relationships in the level of friendship and marriage to disabilities group.

\section{Result and Discussion}

Taking a sample of 415 people from the total active students at Diponegoro University (2020), the respondents in this study were divided into $68.2 \%$ female students and $(31.2 \%)$ male students, where it will be seen whether there is a difference between women and men in acceptance of persons with physical or mental disabilities in building intimate relationships, namely friendship and marriage.

Based on gender background, in general it can be said that there is almost no social distance between Undip students and persons with physical or mental disabilities. However, based on the different tests conducted, there were differences between male and female students, especially in responding to the acceptance of intimate relationships towards persons with mental disabilities, both to build friendships and to get married. Meanwhile, there is no difference between female students and male students in responding toward persons with physical disabilities to build friendships.

Table 1. Acceptance to Establishing Friendship Among Undip Student Towards Physical Disability Group

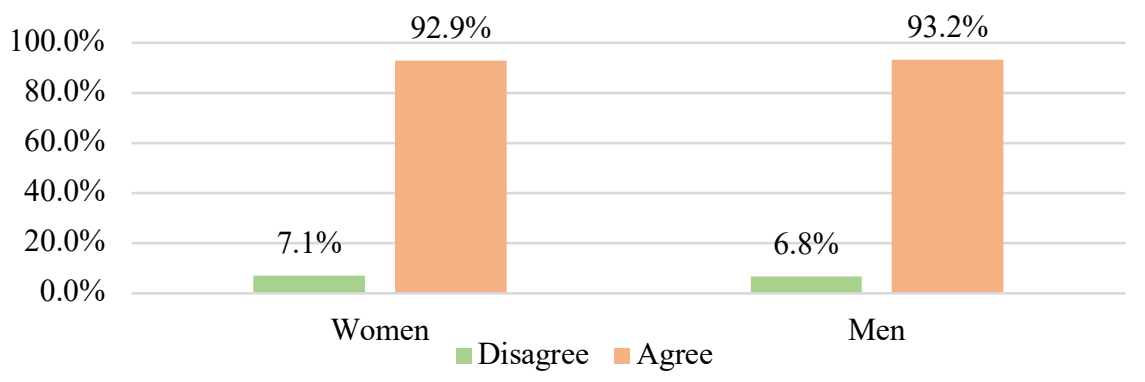


In the scope of friendship, in general (see at Table 1), Diponegoro University students, both male and female, do not have social distance toward disability group. This can be seen in data which shows more than $90 \%$ accept groups with physical disabilities as friends. The percentage of resistance to persons with physical disabilities as friends between women and men was almost as low, namely $7.1 \%$ for female students and $6.8 \%$ for male students. Of the 415 respondents, 29 respondents refused to build friendships toward persons with physical disabilities. Meanwhile, there was a significant increase in the resistance to building friendships by Undip students towards persons with mental disabilities (see at Table 2), especially female students. As many as $32.9 \%$ of female students refuse to be friends, while only $14.4 \%$ of male students.

Table 2. Acceptance To Establishing Friendship Among Undip Student Towards Mental Disability Group

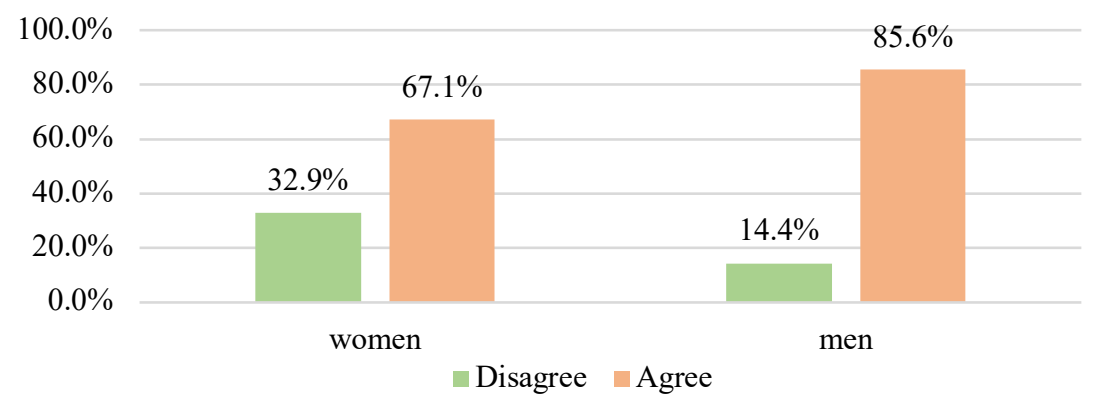

Meanwhile, within the scope of marriage, there is significant rejection of persons with physical and mental disabilities (see at Table 3). In contrast to the desire to build friendships, the percentage of respondents who refuse is much higher than those who accept the idea of the possibility of establishing an intimate relationship, namely marrying a person with physical or mental disabilities. For the desire to marry into a person with physical disabilities, for example, $64.7 \%$ of female students refused, while as many as $53 \%$ of male students also refused. From 415 respondents, 253 respondents refused to marry persons with physical disabilities. Based on the data, it is also seen that women tend to be more distant than men.

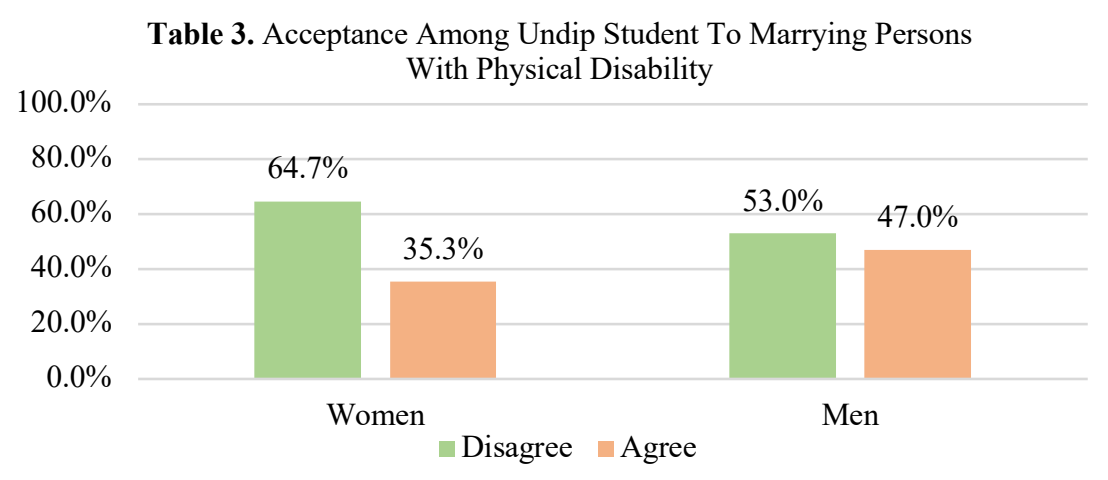

The same thing is seen in the percentage of Diponegoro University students, both male and female, who reject marriage toward persons with mental disabilities (see at Table 4). In fact, the percentage is very high, namely $84.5 \%$ female students, $73 \%$ male students, higher than their attitude towards people with physical disabilities. However, both men and women have 
the same resistance to the idea of marrying someone with a mental disability. Out of 415 respondents, 326 refused to marry people with mental disabilities.

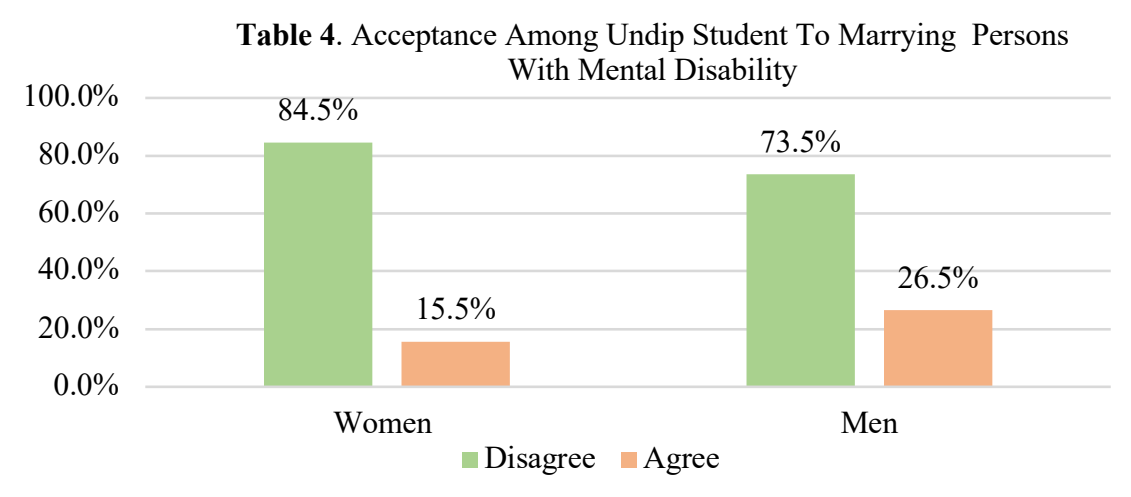

The findings of this study confirm that the social distance in the relationship between Diponegoro University students and persons with physical disabilities is categorized as low. Meanwhile, social distance in the relationship between Diponegoro University students and groups with mental disabilities is categorized as high. Likewise, with prejudice. The majority of respondents are willing to establish interpersonal relationships within the scope of friendship, but not for marriage. Respondents tend to have higher rejection of persons with mental disabilities than groups with physical disabilities. Another interesting finding is that men are more open to building intimate relationships with persons with physical and mental disabilities than women.

In further tracing the data, it was conveyed that the reason for resistance that was most often cited was difficulty communicating toward persons with mental disabilities, another unique reason was the worry of offending feelings during the friendship journey due to their physical limitations. Especially for a more intimate relationship such as marriage, the main consideration is a matter of heredity. As we all know one of the goals of marriage is to carry on offspring. Concern about genetic factors is a major problem. In addition to answering the question of why men are less socially distant, this is because of the social role in the household, as well as the dominance in relationships placed on men, so that as long as men are in normal circumstances, there is a higher possibility of getting married. This then explains the existence of group discrimination with disabilities, especially mental disabilities in an effort to build intimate relationships in interpersonal relationships. The disable group will always receive stereotypes or labels as incompetent or not suitable partners to be invited into the intimate relationship level.

\section{Conclusions}

This study aims to measure the social distance and prejudice of Diponegoro University students in the scope of friendship and marriage based on sex towards groups with physical and mental disabilities. The conclusion that can be conveyed in this study is that in the context of interpersonal relationships (friendship and marriage), the majority of students from different gender backgrounds open spaces for friendship with disable group. However, they tend to be resistant to the possibility of marrying persons with disabilities, especially people with mental 
disabilities. Another interesting finding is that men are more open to building intimate relationships with people with physical and mental disabilities than women. This then explains the existence of group discrimination with disabilities, especially mental disabilities in an effort to build intimate relationships in interpersonal relationships. The disable group will always receive stereotypes or labels as incompetent or not suitable partners to be invited into the intimate relationship level.

\section{References}

[1] R. Erber and M. Erber, Intimate relationships: Issues, theories, and research. Psychology Press, 2016.

[2] S. S. Brehm, Intimate relationships. Mcgraw-Hill Book Company, 1992.

[3] P. Florsheim, Adolescent romantic relations and sexual behavior: Theory, research, and practical implications. Psychology Press, 2003.

[4] E. B. Hurlock, "Psikologi perkembangan," Jakarta: erlangga, 1980.

[5] C. Fulford and V. Cobigo, "Friendships and intimate relationships among people with intellectual disabilities: A thematic synthesis," J. Appl. Res. Intellect. Disabil., vol. 31, no. 1, pp. e18-e35, 2018.

[6] D. H. Rintala et al., "Dating issues for women with physical disabilities," Sex. Disabil., vol. 15, no. 4, pp. 219-242, 1997.

[7] N. Karakayali, "Social distance and affective orientations 1," in Sociological Forum, 2009, vol. 24, no. 3, pp. 538-562.

[8] L. A. Samovar, R. E. Porter, E. R. McDaniel, and C. S. Roy, Communication between cultures. Nelson Education, 2017.

[9] S. C. Simplican, G. Leader, J. Kosciulek, and M. Leahy, "Defining social inclusion of people with intellectual and developmental disabilities: An ecological model of social networks and community participation," Res. Dev. Disabil., vol. 38, pp. 18-29, 2015.

[10] F. C. Mamali, M. Chapman, C. M. Lehane, and J. Dammeyer, "A National Survey on Intimate Relationships, Sexual Activity, and Sexual Satisfaction Among Adults with Physical and Mental Disabilities," Sex. Disabil., vol. 38, no. 3, pp. 469-489, 2020.

[11] C. Friedman and M. C. Rizzolo, "Friendship, quality of life, and people with intellectual and developmental disabilities," J. Dev. Phys. Disabil., vol. 30, no. 1, pp. 39-54, 2018.

[12] E. Ignagni, A. Fudge Schormans, K. Liddiard, and K. Runswick-Cole, "“Some people are not allowed to love': intimate citizenship in the lives of people labelled with intellectual disabilities," Disabil. Soc., vol. 31, no. 1, pp. 131-135, 2016.

[13] M. McCarthy, "Women with intellectual disability: Their sexual lives in the 21 st century," $J$. Intellect. Dev. Disabil., vol. 39, no. 2, pp. 124-131, 2014.

[14] F. R. P. P. Sitorus, "Perubahan Nilai dan Orientasi Masyarakat dalam Penerimaan Disabilitas," J. Ilmu Sos., vol. 4, no. 1, 2017.

[15] H. D. Sulistyani, T. Rahardjo, and L. R. Rahmiaji, "The Social Distance of Diponegoro University Students toward Minority Ethnic Groups," in ICISPE 2019: Proceedings of the 4th International Conference on Indonesian Social and Political Enquiries, ICISPE 2019, 21-22 October 2019, Semarang, Central Java, Indonesia, 2020, p. 162.

[16] W. M. Chernomas, D. E. Clarke, and S. Marchinko, "Relationship-based support for women living with serious mental illness," Issues Ment. Health Nurs., vol. 29, no. 5, pp. 437-453, 2008.

[17] W. L. Neuman and L. Kreuger, Social work research methods: Qualitative and quantitative approaches. Allyn and Bacon, 2003. 